\title{
A Study on Online Purchasing Behavior in JD.com
}

\section{Duan Ge}

Faculty of Business and Accountancy, Lincoln University College, Kuala Lumpur, Malaysia

Email: duangebj@qq.com

How to cite this paper: Ge, D. (2022). A Study on Online Purchasing Behavior in JD.com. Open Journal of Business and Management, 10, 466-500. https://doi.org/10.4236/ojbm.2022.101027

Received: December 9, 2021

Accepted: January 26, 2022

Published: January 29, 2022

Copyright (c) 2022 by author(s) and Scientific Research Publishing Inc. This work is licensed under the Creative Commons Attribution International License (CC BY 4.0).

http://creativecommons.org/licenses/by/4.0/

\begin{abstract}
Online shopping or purchasing is a human activity where people buy goods, products, or services through the Internet. In this time, individuals are increasingly transitioning to online shopping or purchasing alongside the development of different websites (Tsai, Janice, \& Egelman, 2001). The objective of this research is to explore the characteristics of online purchasing behaviors, factors affecting these behaviors, and the extent of the impact of these factors in JD.com, which is one of China's biggest and largest online purchasing platforms (JD.com, n.d.). The respondents of this research were individuals who are customers of JD.com or individuals who have the experiences or intention of purchasing on the same platform. The qualitative analysis of this research reveals that four characteristics of online purchasing behavior in the case of JD.com are present. First, the customers of online purchasing in JD.com pay more attention to the quality of the goods. Second, the price is the most important factor. The results of the multiple linear regression model and principal component analysis show that there are three indirect factors of online purchasing behaviors. These are the affect factors, social factors, and perceived risk factors. These three factors influence online purchasing behaviors through influencing online purchasing intention. Moreover, there are also three direct factors of online purchasing behaviors. These are the habits, facilitating conditions, and online purchasing intentions. Further, results show that the influences of all six factors are significant. In conclusion, JD.com and other online shopping platforms can use the result of this research and pay attention to the six factors affecting online purchasing behaviors to improve a company's services and increase the number of its customers.
\end{abstract}

\section{Keywords}

JD.com, Online Shopping, Online Purchasing, Factors of Online Purchasing Behaviors 


\section{Introduction}

\subsection{Background}

In this time, individuals are increasingly transitioning to online shopping or purchasing alongside the development of different websites (Tsai, Janice, \& Egelman, 2001). Throughout multiple transitions, a series of changes in purchasing behaviors and purchasing concepts are being observed. The quick development of online purchasing provides companies with a new chance to adapt and improve. As a new form of shopping, it offers different companies a new sale channel where people could purchase. More than the traditional way of shopping, the occurrence of online purchasing gives a wider set of choices to the customers, but at the same time, it makes the purchasing process more complex (Tsai, Janice, \& Egelman, 2001). With various online shopping research studies available to us, the common goal of these researchers is to improve or develop the online retail industry or e-commerce.

In 2021, Yihan Ma cited data from Statista showing that China accumulated 782.41 million online shoppers from 2009 to 2020 . These numbers show that the e-commerce in China is fast-growing (Sun et al., 2021). This growth has resulted in increase in online shopping opportunities in the country (Ma, 2021). Despite the growth of online shopping in China compared with other developing countries, research on this matter is still necessary as it still has gaps that need to be filled, considering the quick development and wide potential for the future improvement of Chinese online shopping (Chiu \& Choi, 2018). These gaps include the influence of factors that affects the online behaviors in China. In 2010, there were more than 420 million online users in China, which is 2.6 million more than in 2018. Also, more than $18 \%$ of online users say they have experience in online purchasing (Chiu \& Choi, 2018). With these numbers, it can be concluded that there is a huge potential business profit in online transactions. In fact, online shopping has already become an important marketing channel in China (Chiu \& Choi, 2018). For this reason, this research chose a Chinese case to explore and understand the online purchasing behaviors in China.

China has a large number of online shopping malls and websites, such as Taobao and JD.com. For this research, the subject of the study is JD.com, which is one of China's biggest and largest online purchasing platforms (JD.com, n.d.). JD.com is a comprehensive online shopping platform that focuses on the online retail industry in China. The customers can purchase more than 40.2 million goods with a wide range of brands. The JD.com shopping platform contains 13 categories, including household electrical appliances, clothing, and mobile phones. It can meet all the needs of customers and offer them a one-stop service. Its annual turnover reaches 53.9 billion dollars in the year 2018. The characteristics of JD.com are its own delivery service which improves the delivery speed, and its offline JD.com shopping mall, which improves the reliability of JD.com. 


\subsection{Problem Statement}

There is already much research summarizing the factors affecting online purchasing behaviors, and claiming a series of valuable conclusions. However, some research gaps are still present in this field. One of which includes the research about how these factors influence online purchasing behaviors and what is the limitation and extent of the impact of these factors. Also, empirical research on this topic is needed since most of the research focuses on European areas and other developing countries, which causes the inadaptability of the conclusions to other countries. The object of this research is JD.com online shopping platform. Its purpose is to explore and understand the online purchasing behaviors of online buyers in this specific platform, as well as its characteristics and factors. To fill in the research gaps in this field, this research gave attention to exploring and understanding how these factors influence online purchasing behaviors and what is the extent of the impact of these factors using quantitative and qualitative methods.

\subsection{Research Question}

Generally, this study aims to determine the factors of online purchasing behaviors and the extent of the impact of these factors using the case study of JD.com. Specifically, there are three questions in this research. Firstly, this study explores the characteristics of online purchasing behavior in JD.com through qualitative analysis. Secondly, it explores the factors of online purchasing behavior in JD.com by summarizing the past research studies available to us. Thirdly, it explores the extent of the impact of these factors and finds out the significant factors through principal component analysis and multiple linear regression models.

\subsection{Research Objective}

The objective of this research is to explore the characteristics of online purchasing behaviors, factors affecting these behaviors, and the extent of the impact of these factors on JD.com. Through the use of the JD.com case study, this research reveals the factors that can directly and indirectly influence online purchasing behaviors. It also provides suggestions about how online shopping malls can attract more customers and decrease the danger in online purchasing through improving these factors.

\subsection{Research Hypothesis and Significance of the Study}

This research claims the following hypothetical relationships as shown in Figure 1.

Hypothesis 1: There is a significant influence of some factors, such as feeling factors, social factors, and risk factors, in online purchasing intention.

Hypothesis 2: There is a significant influence of some factors, such as habit, facilitating condition, and purchasing intention, in online purchasing behaviors. 


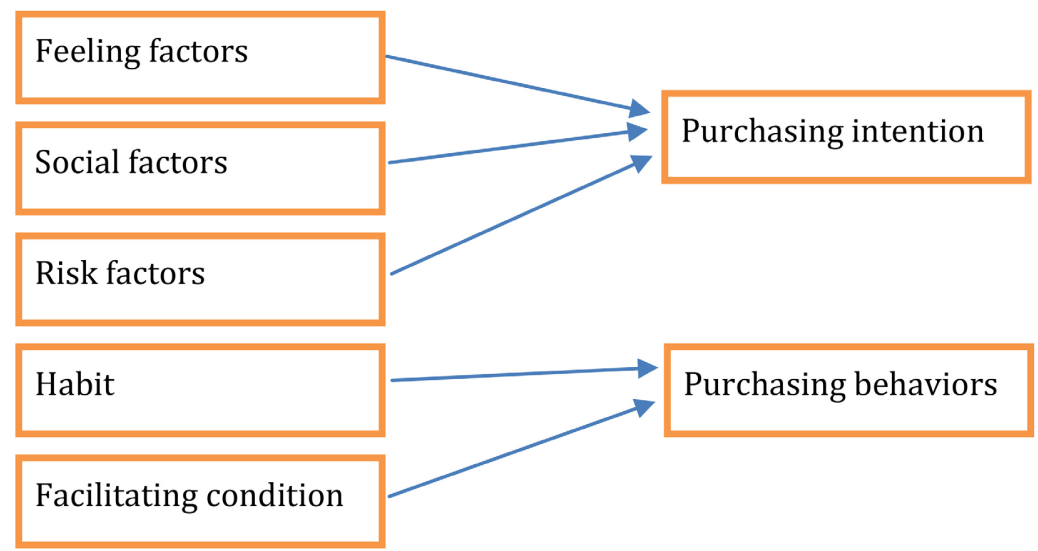

Figure 1. The hypothetical relationship between factors and online purchasing behaviors.

In Figure 1, the arrow indicates the presence of a relationship between factors and purchasing behaviors.

This research has three significances. First, it will provide a theoretical basis of online purchasing behaviors for online shopping malls for the creation of their marketing strategies in the future by summarizing the factors of online purchasing behaviors. Second, it will explain the relationship and degree of correlation between factors and online purchasing behaviors. Both online shopping platforms and offline shopping malls can use this degree of correlation to attract more customers. Thirdly, it can provide reference data for future research studies and point at the limitation as well as the future research direction about this topic.

\subsection{Organization of the Thesis}

To achieve the aim of this research, the researcher had to follow the steps accordingly. Firstly, it should determine the research questions and research objective after analyzing the theoretical and realistic research background. Secondly, it should collate the correlative review of related studies, literature, and information. Thirdly, it should ensure the frame and the design of the research. Fourthly, it should determine the model and methodology of the research. Fifthly, it should design and post the questionnaire about the research object. Sixthly, it should analyze the data of the questionnaire and make models using the collected data of the case study. The models include principal component analysis and multiple linear regression models. Lastly, it should summarize the findings and recommendations of this research study (Figure 2).

\section{Literature Review}

\subsection{The Introduction of Online Purchasing Behavior}

Online purchasing behavior is the behavior of purchasing a service or goods over a website. Online purchasing behavior means a new purchasing method through the internet (Tsai, Janice, \& Egelman, 2001). The whole process of 


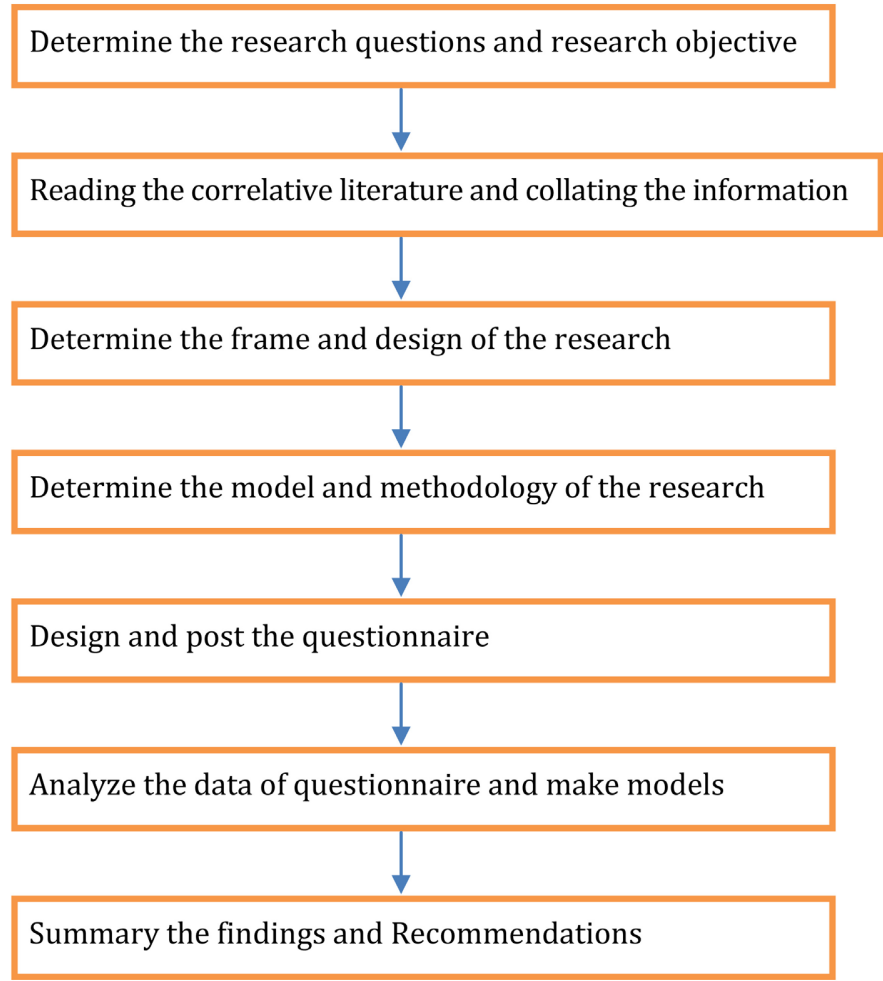

Figure 2. The organization of the thesis.

online purchasing behavior, including communication, paying the money, and delivery, are all completed on the website. The influences of customers, individuals, consumption, and society still extend in online purchasing behavior (Tsai, Janice, \& Egelman, 2001). However, these influences are different from the influences in offline purchasing behavior. Hoffman, Kalsbeek, and Novak (1996) divided the differences into the following four characteristics: the population factor, customer factor, transaction security factor, and efficiency of delivery factor.

The population factor includes the education, gender, and salary of the customers (Hoffman, Kalsbeek, \& Novak, 1996). Although with the development of websites most individuals can shop online, exploring the influence of population factors in online purchasing behaviors is still necessary (Tsai, Janice, \& Egelman, 2001). For example, there is a positive relationship between the salary of online shopping customers and the acceptable price of goods in the online mall. Another example is when young people spend more time on the website than the old. Therefore, shopping websites focusing on young customers should have a personalization option and be more complex, while shopping websites focusing on the old should be simple.

Customer factor includes four parts of online shopping, namely the society experience, communication about information, website experience, and convenience of the online shopping (Hoffman, Kalsbeek, \& Novak, 1996). The customers who pay attention to convenience are more likely to choose online purchas- 
ing behaviors than the customers who pay attention to the social experience.

The transaction security factor includes the security of information, which is the recognized key problem of online purchasing behaviors (Ramin, Darush, \& Mohammad, 2011). Ramin, Darush, and Mohammad (2011) claim that customers prefer to choose goods with low prices to decrease the risk. The increasing attention of customers towards individual privacy requires the online stores to improve the security of information (Ramin, Darush, \& Mohammad, 2011).

The efficiency of the delivery factor means the duration of transportation after online purchasing behaviors (Hoffman, Kalsbeek, \& Novak, 1996). In fact, there are some gaps in the efficiency of delivery in China compared with the developed countries (Chiu \& Choi, 2018). Low efficiency of delivery negatively impacts the online purchasing behaviors because the customers have to spend more time waiting for the goods to arrive, and the customers have to take the risk of possible wrong delivery (Hoffman, Kalsbeek, \& Novak, 1996).

\subsection{The Characters of Online Purchasing Customers}

Online purchasing behaviors are the summary of searching information, shopping style, shopping place, and shopping experience. In the background of online shopping, the mentality, and behaviors of the customers turn to have some new characteristics and tendencies (Glandon \& Haynes, 2005). There are four characteristics of online purchasing customers.

First, the customers of online purchasing behaviors pay attention to personalization. In offline stores, the choices of customers are limited. Thus, the customers have to ignore their requirements about personalization. With enough information on the website and a wide range of choices, the customers can choose both services and goods based on their preference (Glandon \& Haynes, 2005). That is why they choose other extended services and goods instead of just the goods themselves. The extended services include their personality and the sense of identity.

Second, the initiative of customers increases. With the improvement of humanistic quality in China, customers turn to research information and compare information initially. Also, the perceived risk increases with the increasing choice of goods (Ramin, Darush, \& Mohammad, 2011). In the normal purchasing process, especially when purchasing expensive goods, customers initially gain information about the goods through different ways and compare this information before finally. Although the comparison and analysis of customers may not be accurate, they can still get the mental balance and the satisfaction towards goods that can be increased through this initial comparison process (Ramin, Darush, \& Mohammad, 2011).

Third, price is the most important factor of online purchasing behaviors. For the customers, both the shopping environment and shopping way can be chosen and changed. The customers can choose to accept, reject, or negotiate the price. If the price of goods in the online malls is similar to the price of goods in the 
physical stores, the customers will prefer to keep their purchasing intention (Glandon \& Haynes, 2005). If the price of goods in the online malls is lower than the price of goods in the physical stores, the customers would be attracted.

Fourth, the stability of online purchasing intention is lower than the stability of offline purchasing intention. Since the website brings enough information about the goods, there are many choices available to customers. The purchasing behaviors towards interests, hobbies, and personal experience increase (Glandon \& Haynes, 2005). Additionally, the speed of purchasing behaviors increases, and the process of purchasing behaviors is shortened.

\subsection{The Factors of Online Purchasing Behavior}

Jarvenpaa, Sirrka, and Peter (1996) combine the feeling of goods, shopping experience, and customer service. They confirmed that the above-mentioned factors can influence online purchasing behaviors. Also, some research studies pay attention to obvious characteristics of online purchasing behaviors, such as the convenience of online purchases, huge information, and fully competitive prices. Generally, these above advantages positively influence online purchasing behaviors. The disadvantages like transaction cost and delivery cost negatively influence online purchasing behaviors.

Through analyzing the review literature, there are three main theories of online purchasing behaviors that are discovered: Perceived Risk theory, S-O-R Theory, and Intention Theory. Perceived Risk Theory focuses on the perceived risk of online purchasing behaviors. S-O-R Theory researches based on environmental psychology. By contrast, Intention Theory assumes the behaviors of individuals using the factors of individual behavior intention.

\subsubsection{Perceived Risk Theory}

Perceived Risk is used to explain the behaviors of customers from the 1960s because when the customers purchase goods, they cannot assume the results of using the goods. They take the risk of purchasing, which is the internal meaning of perceived risk theory. There is a large amount of research finding the relationship between perceived risk and online purchasing behavior. They suggested that when the customers cannot predict whether using the goods can achieve their purchasing objectives, the customers become worried about their purchasing behaviors. Cox and Rich (1964) summarized that the perceived risk is the total feeling of the risk in the process of shopping. In the 1990s, researchers explored online purchasing behaviors based on this theory. They suggested that the perceived risk is one of the factors in explaining and stopping online shopping (Kandampully \& Butler, 2001). Kandampully and Butler (2001) defined that the perceived risk is the subjective judgment of customers about the expected shopping loss when they purchase in online malls.

There are four types of perceived risk: expected loss of finance, time, the goods' performance, and mentality (Lopez-Nicolas \& Francisco, 2008). The ex- 
pected loss of finance includes the possible loss of credit cards, which is the primary risk of finance. The customers do not prefer to provide information about their credit cards. This is one of the biggest barriers to online shopping. The expected loss of goods' performance means the unsatisfactory consequence of customers' purchase of goods with poor quality. Also, if the information about the goods is lacking, the expected loss of goods' performance may increase. The expected loss of mentality includes disappointment and anger because of information disclosure, which is from the idea that some customers may think that the information is disclosed when purchasing online. This decreases the customers' ability to provide their information to the website businesses (Lopez-Nicolas \& Francisco, 2008).

Krairiksh and Anthony (2001) divided the perceived risk into abuse of credit cards, cheating in the website, information disclosure, the problem of delivery, and the failure of goods. Krairiksh and Anthony (2001) suggested that the main barriers to perceived risk are the risk of information disclosure and security risk through exploring the relationship between perceived risk and online purchasing behaviors. In conclusion, perceived risk has a negative influence on online purchasing behaviors because it can influence purchasing intention, which can positively impact online purchasing behaviors.

\subsubsection{The S-O-R Theory}

The S-O-R Theory is Stimulus-Organism-Response Theory. In the 1970s, research studies were explaining that there is a relationship between the environments and purchasing behaviors because the shopping environment can impact the emotional expression of the customers like the feelings of encouragement, pleasantness, and superiority (Mehrabian \& Russell, 1974). In the S-O-R Theory, the stimulus is the impetus of arousing emotion and individual behaviors. Mehrabian and Russell (1974) divided the stimulus factors of the shopping environment into three types: the society factors, the design factors, and the surrounding factors. In this theory, the society factors include other customers and shop assistants. The design factors cover the color and the decoration of the store. The surrounding factors cover the light, the smell, and the sound in the store. Bitner and Mary (1992) claimed another three types of stimulus factors of the shopping environment. The first stimulus factor is the five senses of the customers. The second stimulus factor is the design and function. This refers to whether or not the equipment of the store is convenient for customers to research on their available goods. The third stimulus factor includes nameplates and service marks that show the internal and external signals of communication with the customers.

Eroglu et al. (2003) claimed a hypothesis about online purchasing behavior based on the S-O-R Theory. The hypothesis is that the factor of the environment in the online mall makes the same effect as in the physical store. The stimulus factors in the online shopping environment are different from the stimulus factors in the physical store (Mehrabian \& Russell, 1974) because the online shop- 
ping environment cannot provide stimulus factors like smell, temperature, and visible shop assistants. In the online shopping mall, the whole shopping environment is based only on what is seen on the computer screen. Eroglu et al. (2003) suggested that some factors of the online shopping environment impact the internal feeling and consideration of the customers. For example, the description of the online store and the evaluation of other customers can motivate or hinder online purchasing behaviors. The online shopping environment has its characteristics, such as flexible time and space. The importance of social factors is also highlighted (Mehrabian \& Russell, 1974). Moreover, the good design of website pages and environment is one of the most important stimulus factors of the shopping environment. Through this, it showed the importance of simplicity and usability of the online store for online purchasing behaviors.

In conclusion, the main idea of the S-O-R Theory is that the environment of online stores directly influences the online purchasing intention of the customers, and it indirectly impacts the online purchasing behaviors.

\subsubsection{Intention Theory}

Intention Theory is considered a good theory in meeting the requirements of research studies explaining online purchasing behaviors. This theory contains the whole process of making online purchasing decisions. Ajzen and Fishbein (2011) suggested that the individual intention is the fittest way to assume the individual behaviors. The behavior's intention is the subjective probability of making behaviors. As the individual intention becomes stronger, the probability of making this behavior also increases. This means that there is a close connection between individual intention and individual behavior (Ajzen \& Fishbein, 2011). In the Intention Theory, the acceptance of the customers on the information of the website page can be assumed, and the online purchasing behaviors can be explained (Ajzen \& Fishbein, 2011).

\section{1) Theory of Reasoned Action}

The Theory of Reasoned Action claimed by Fishbein and Ajzen in the year 1980 is used to assume the behaviors of human beings. They suggested that the intention can influence the behaviors more than beliefs and attitudes as affection. Therefore, knowing the intention of an individual is necessary for assuming their future behaviors. It is explained in this theory that the behavior is influenced by the intention that is why the factors of intention are also necessary to be explained.

The Theory of Reasoned Action assumes that the individual behaviors are rational (Ajzen, 1985) and the behaviors are controlled by the individual intention. However, some factors are influencing the extent of the controlling of intention. Ajzen (1985) suggested that there are two parts to these factors, the endogenous variables, and exogenous variables. Endogenous variables include individual differences, ability, and emotion. The individual difference means that the control ability of individuals is different. Ability is the individual intention that may not 
be achieved because of the shortage of ability. Emotion means that the individual cannot control their behaviors because of bad emotion or intense pressure. By contrast, exogenesis variables include time, chance, and the suggestions of others. The intention can be changed when there is little time and a chance for the individuals. The suggestions of others mean that the purchasing intention can be changed by the suggestion and evaluation of others. Ajzen and Fishbein (1970) also claimed that the purchasing intention influences the purchasing behaviors, and the purchasing intention is impacted by the attitude to the behaviors and the subjective norm.

However, some researchers are criticizing that the Theory of Reasoned Action cannot explain all behaviors. This theory assumes that all of the behaviors are controlled by the minds of the individuals, which could be impossible. Sheppard et al. (1988) considered that there were two problems of the Theory of Reasoned Action. One problem is that the prediction of the behaviors is only through intention and may ignore some other important factors. Another problem is that there are some special situations when individuals cannot make the behaviors according to the intention (Sheppard et al., 1988).

In the research study of Ajzen and Fishbein (1970), the process of Theory of Reasoned Action is shown in Figure 3. The exogenesis variables, the attitude towards goods, the consideration, and the characteristics of a job all impact both attitude of behaviors and the subjective norm. Also, the attitude of behaviors and the subjective norm work together in the intention of behaviors, and it influences actual behaviors.

\section{2) Theory of Planned Behavior}

The Theory of Planned Behavior suggested by Ajzen (1985) is the extension of the Theory of Reasoned Action focusing on customer behaviors. This theory claims that the factors of purchasing behavior influence purchase intention indirectly at first and then influences purchase behavior at the end (Ajzen, 1985). There are three steps of the whole theory. Firstly, the actual behaviors are decided by the intention of behaviors. Secondly, the intention of behaviors is controlled by three factors: the attitude of the individuals, the influence from friends and relatives in purchasing decisions, the perceived behavioral control of the experience. In the end, these three factors are influenced by the exogenesis variables,

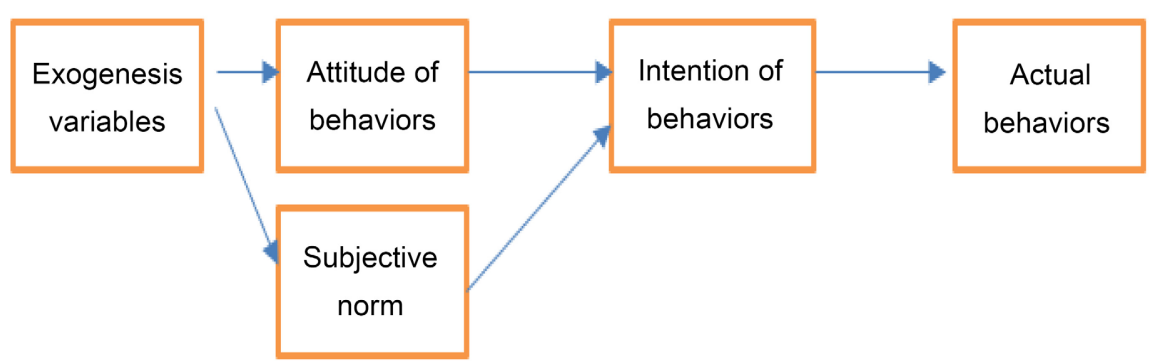

Figure 3. The process of theory of reasoned action. Source: The Prediction of Behavior from Attitudinal and Normative Variables (Ajzen \& Fishbein, 1970). 
including the attitude towards goods, the consideration, and the characteristics of the job (Ajzen, 1985). The whole relationship between these variables is shown in Figure 4.

The attitude of behaviors can be divided into two parts: the attitude towards the goods and the attitude towards the behaviors. There are a large number of researchers confirming that attitude can influence behaviors. If the attitude towards the behaviors becomes more specific, the influence also becomes more significant. Ajzen and Fishbein (2011) suggested that attitude towards things cannot be used to predict the future behaviors of individuals. However, there is a direct relationship between predicting future behaviors and the attitude towards behaviors. If the individual has a positive attitude towards the behaviors, the possibility of making these behaviors is increased (Ajzen \& Fishbein, 1970). Therefore, this theory discusses the attitude towards the behaviors instead of the attitude towards the things.

Subjective norm explains whether or not others can agree with these behaviors when the individuals do some behaviors. It also means the expected pressure from society when the individuals make this behavior. Behaviors can be influenced by the pressure of the environment, including the influence of friends and relatives (Ajzen \& Fishbein, 1970). Sometimes, the influence of the subjective norm is even more important than the attitude towards the behaviors (Ajzen \& Fishbein, 2005).

Besides attitude of behaviors and the subjective norm, the behaviors are also decided by the perceived behavioral control or the extent of controlling of intention towards behaviors. Some behaviors can be controlled by intention. By contrast, some behaviors cannot be controlled by the intention of the individual (Ajzen \& Fishbein, 2005). For example, in one group, the behaviors of group members are influenced by many external factors, including ability, resources, and chance. Therefore, the behaviors cannot be predicted correctly just through subjective norms as well as attitude of behaviors (Ajzen \& Fishbein, 2008).

\section{3) Triandis Model}

Triandis claimed the Triandis Model in 1980 based on the Theory of Reasoned

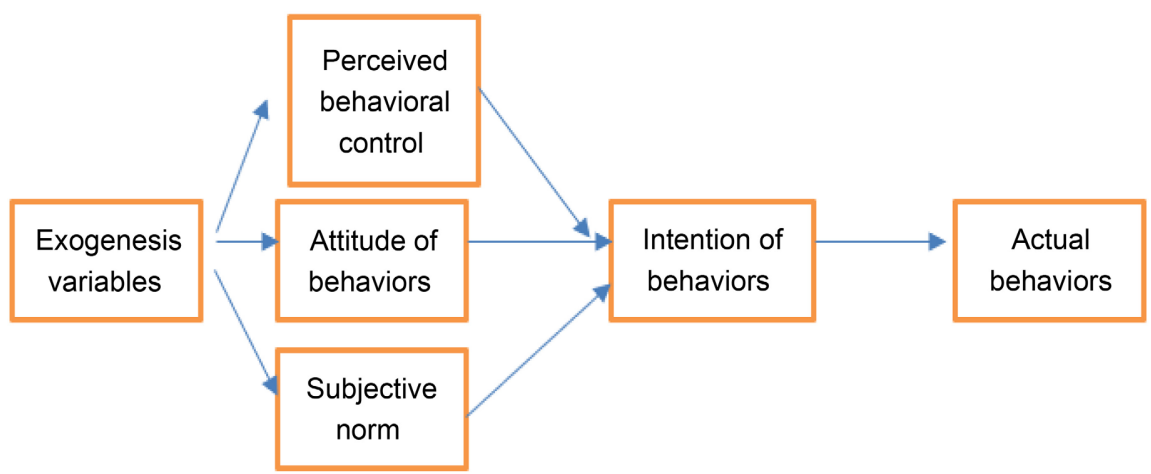

Figure 4. The process of theory of planned behavior. Source: From Intentions to Actions: A Theory of Planned Behavior (Ajzen, 1985). 
Action. Triandis (1980) suggested that the individuals have the intention before making the actual behaviors. The intention of the behaviors is impacted by the attitude towards behaviors. Based on this relationship, Triandis (1980) suggested the Triandis Model. Its main idea is shown in Figure 5. In this model, Triandis (1980) considered that the behaviors are influenced by three factors: habit, facilitating, and intentions. Habit means that the individuals prefer to do the same behaviors in a specific situation. Facilitating conditions means whether or not there are conditions for the individuals to do this behavior or this behavior is easy to be achieved. According to the research of Triandis (1980), even if the individuals have strong intentions to do some behaviors, if there are some barriers in the situation like the limitation of time and space, the behaviors can be difficult to do.

In addition, the intentions towards the behaviors can be impacted by the social factors, perceived consequences, and affect factors. Social factor means whether or not the behaviors can be agreed upon by the culture and others. This meaning is similar to the meaning of the subjective norm in the Theory of Planned Behavior. This factor is used to explain whether or not this individual is considered to be suitable to do this behavior. Perceived consequence means the value of the behaviors for the individuals. Triandis (1980) suggested that the more important perceived consequence is, the more possible the individuals will do this behavior, and the perceived consequence may either be loss or gain. The perceived consequence is the consideration based on the knowledge. By contrast, the affect factor is the internal feeling of the individuals. It explains why there are some good behaviors not being done and why some bad behaviors are being done. Some good perceived consequences may not bring good effects for the individuals. As a consequence, there may be a conflict between these two factors.

The biggest difference between the Triandis Model and the Theory of Reasoned Action is that the Triandis Model includes emotional factors. By contrast, the Theory of Reasoned action assumes that the individuals are rational.

\subsection{The Summary of Literature Review}

In this part, this research reviewed the past literature about online purchasing

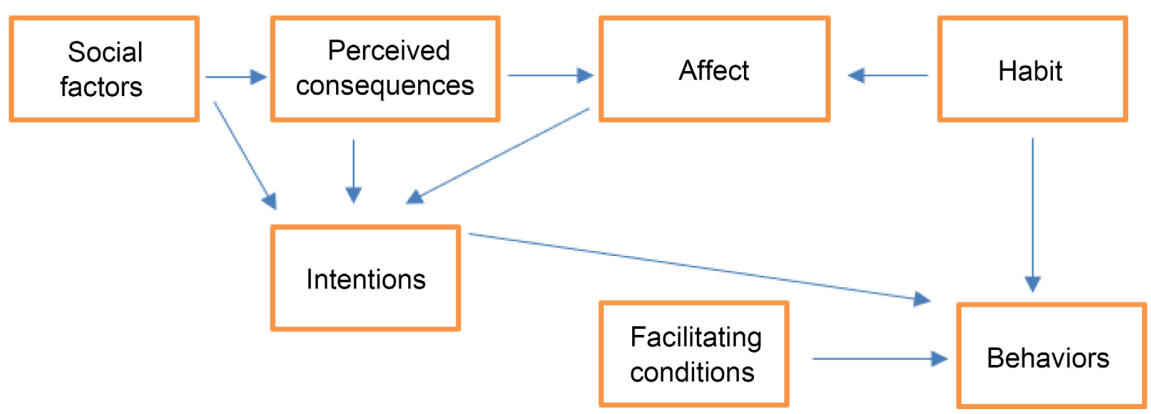

Figure 5. The process of Triandis model. Source: Triandis Model in 1980 based on the Theory of Reasoned Action (Triandis, 1980). 
behaviors. It first summarized the four characteristics of online purchasing behavior according to the research of Hoffman, Kalsbeek, and Novak (1996). Then it discussed the four characteristics of online purchasing customers based on the research studies of Glandon and Haynes (2005) and Ramin, Darush, and Mohammad (2001). Afterward, it reviewed the main theory of this topic, including perceived risk theory, Stimulus-Organism-Response Theory (S-O-R Theory), and Intention Theory.

With the development of online shopping, there is a large number of research studies exploring online purchasing behaviors. In this literature review, the researcher mainly discussed the eight theories mentioned. The details of these theories are also shown in Table 1.

\section{Methodology}

\subsection{Research Design}

This research employed a mixed method of quantitative and qualitative analysis. It also used a correlational approach. Table 2 specifically states the design of this research.

\subsection{Population and Sample Size}

This research chose JD.com as a case study of online purchasing behaviors. The respondents of this research were the customers of JD.com or the individuals

Table 1. The main theories of the literature review.

\begin{tabular}{|c|c|c|}
\hline Author & Year & Theory \\
\hline $\begin{array}{l}\text { Hoffman, Kalsbeek, and } \\
\text { Novak }\end{array}$ & 1996 & $\begin{array}{l}\text { Four characters of online purchasing } \\
\text { behavior: population factor, customer } \\
\text { factor, transaction security factor and the } \\
\text { efficiency of delivery factor }\end{array}$ \\
\hline $\begin{array}{l}\text { Glandon and Haynes; } \\
\text { Ramin, Darush and } \\
\text { Mohammad }\end{array}$ & $2005 ; 2001$ & $\begin{array}{l}\text { Four characteristics of online purchasing } \\
\text { customers: pay attention to the personality, } \\
\text { initiative of customers increase, price keeps } \\
\text { important, lack of stability }\end{array}$ \\
\hline $\begin{array}{l}\text { Lopez-Nicolas and } \\
\text { Francisco; } \\
\text { Krairiksh and Anthony; } \\
\text { Kandampully and Butler }\end{array}$ & $2008 ; 2001 ; 2001$ & Perceived Risk Theory \\
\hline $\begin{array}{l}\text { Mehrabian and Russell; } \\
\text { Eroglu et al.; Bitner and } \\
\text { Mary }\end{array}$ & $1974 ; 2003 ; 1992$ & $\begin{array}{l}\text { Stimulus-Organism-Response Theory } \\
\text { (S-O-R Theory) }\end{array}$ \\
\hline Ajzen and Fishbein & 2011 & Intention Theory \\
\hline $\begin{array}{l}\text { Ajzen and Fishbein; } \\
\text { Ajzen }\end{array}$ & 1970; 1985 & Theory of Reasoned Action \\
\hline Ajzen and Fishbein & $\begin{array}{c}1970 ; 2005 ; 2008 ; \\
2011\end{array}$ & Theory of Planned Behavior \\
\hline Triandis & 1980 & Triandis Model \\
\hline
\end{tabular}


Table 2. The design of the research.

\begin{tabular}{rll}
\hline Step & \multicolumn{1}{c}{ The Purpose of This Step } & \multicolumn{1}{c}{ Method } \\
\hline 1 & $\begin{array}{l}\text { The characteristics of online } \\
\text { purchasing behavior in JD.com }\end{array}$ & Qualitative Analysis \\
2 & $\begin{array}{l}\text { The factors affecting online purchasing } \\
\text { behavior in JD.com }\end{array}$ & Qualitative Analysis \\
& $\begin{array}{l}\text { The influence of factors in purchasing } \\
\text { intention }\end{array}$ & $\begin{array}{l}\text { Multiple Linear Regression Model and } \\
\text { Principal Component Analysis }\end{array}$ \\
4 & $\begin{array}{l}\text { The influence of factors in purchasing } \\
\text { behavior }\end{array}$ & Using multiple linear regression model
\end{tabular}

who have the experiences or intention of purchasing on the same platform. It included students, teachers, and employees. Until December in the year of 2019, an initial of 100 questionnaires, which are made up of 67 online questionnaires and 33 offline questionnaires, were given out to the 100 people.

\subsection{Instruments}

The instruments for the data collection in this research include the past research and questionnaire. Through the past literature, the researcher collected and summarized the factors of online purchasing behaviors. Using the questionnaires administered through online social media and offline platforms. The questionnaire utilized the five-point Likert scale. To increase the rate of returning the questionnaires, the researcher used an interview schedule for the interview of the individuals who spend a long time on the website.

\subsection{Proposed Data Analysis}

This research study mainly used quantitative methods, the method of principal component analysis, and a multiple linear regression model to analyze the data collected. This also used SPSS Statistics 20 as an instrument to analyze the quantitative data. It also used the following mathematical methods: the description of the data, which includes min, max, mean and standard deviation. The mean showed the average attitudes towards the factors of JD.com. The standard deviation of the data showed the differences of the customers in the website of JD.com. The min and max showed the best and worst attitudes towards the online shopping mall of JD.com. The method of principal component analysis is used to reduce the number of factors. Through the method of principal component analysis, the factors can be expressed by the principal components, and the principal components can be used to make a multiple linear regression model. $\mathrm{R}$ square, standard error, and Durbin-Waston are used to measure whether the model can explain the purchasing intention well, whether the coefficients of this model are stable and effective, and whether there is a sequence correlation of error in this model. 


\subsection{Questionnaire Design}

The questionnaire will use the method of a five-point Likert scale to measure the attitude of interviewees towards questions. The coding of each score is shown in Table 3.

The six factors that may influence the online purchasing behaviors in JD.com, which were collected from previous research studies, are used as the basis of the design of close-ended questions. These are affect factors, social factors, perceived risk factors under the indirect factors of online purchasing behaviors, and habit, facilitating condition, online purchasing intention under direct factors of online purchasing behaviors. Ajzen and Fishbein (2011) suggested that this method of the questionnaire is effective in collecting data, hence the researcher's use of a questionnaire.

\subsection{Summary}

The five parts of this chapter introduced the methods and methodology of this research.

\section{Analysis Data}

\subsection{Returned and Unreturned Questionnaire}

In 100 copies of questionnaire given to 100 people, 42 questionnaires were completely filled. This means that the rate of effective questionnaires is $42 \%$.

\subsection{The Characters of Online Purchasing Behavior in JD.com}

According to the report of online purchasing behavior of JD.com in 2016 and based on the large data analysis, this thesis summarizes the following characteristics of online purchasing behavior in JD.com.

First, the customers of online purchasing in JD.com pay more attention to the quality of the goods. Through the large data analysis, the main customers range from 26 years old to 35 years old. The characteristics of these customers focus on the quality of the goods. They pay attention to cultural consumption and diversified consumption. Most of them can accept foreign goods. In terms of profession, there are a large number of white-collar workers of online purchasing groups in JD.com. Moreover, there are many students and teachers online purchasing

Table 3. The coding of each score.

\begin{tabular}{cc}
\hline Score & Coding \\
\hline 1 & Strongly Disagree \\
2 & Disagree \\
3 & Neutral \\
4 & Agree \\
5 & Strongly Agree \\
\hline
\end{tabular}


on JD.com. Through the report of the online purchasing behavior of JD.com in 2016, the customers of online purchasing in JD.com turn out to be rational. In China, the customers of some developed areas, such as Beijing and Shanghai, pay more attention to the quality of the goods compared with the customers of other developing areas.

However, the price is still the most important factor to attract online purchasing customers of JD.com. The positive influence of low prices in attracting customers is significant. The promotional activities are effective to increase the online purchasing behaviors in JD.com.

There are different characteristics of the online purchasing behavior of JD in different cities. In first-tier cities, the customers pay more attention to the brands. The structure of consumption is more comprehensive, including food and makeup. In the second-tier cities and third-tier cities, the requirement of online purchasing improves quickly because of fewer life pressures than first-tier cities, and more disposable income than fourth-tier cities. The requirement of household appliances and communication equipment of the fourth-tier cities increases quickly. However, the requirements for fresh food in the fourth-tier cities have increased because of the lack of consumption habits and consumption trends of the customers there.

In addition, the quick speed of development is another character of online purchasing behavior in JD.com. The consumption of some cities has already been greater than the consumption of some developed countries. The consumption of western areas also increases quickly. In 2016, the whole amount of online consumption in China ranked first in the world, which is more than 2000 billion RMB. This gives JD.com a big chance to develop its online shopping platform and environment.

Moreover, there are some new trends in the online purchasing behavior of JD.com. For example, Mobile consumption has become popular in online purchasing behavior in JD.com with the development of communication equipment, which may become the trend in the future.

In summary, there are four characteristics of online purchasing behavior in the case of JD.com. The first is that the customers of online purchasing in JD.com pay more attention to the quality of the goods. Another characteristic is that the price is still the most important factor. The third is that there are different characteristics of the online purchasing behavior of JD.com in different cities. The last characteristic is the quick speed of website development.

\subsection{Identify the Factors of Online Purchasing Behavior}

Through the literature review, there are three indirect factors of online purchasing behaviors: affect factors, social factors, and perceived risk factors. These three factors influence online purchasing behaviors through influencing online purchasing intention. Moreover, there are three direct factors of online purchasing behaviors: habit, facilitating condition, and online purchasing intention. 


\subsubsection{Identify the Factors of Purchasing Intention}

The Affect Factors can positively influence the purchasing intention. Through the theory of Triandis (1980), affect factors can directly influence the tendency of the individuals' behaviors. It is a comprehensive feeling which combines like, interest, pride, hate, failure, and loathe. Triandis (1980) suggested that affect is the direct emotion towards online purchasing behaviors because individuals usually turn to do the behaviors towards which they have positive attitudes. It can be measured by these three indexes: whether the customers are interested in online purchasing behaviors, whether the customers think online purchasing behaviors are interesting, and whether the customers like online purchasing behaviors. Ajzen and Fishbein (2011) also suggested that the affect factor is very important in predicting future purchasing behaviors. He suggested that the affect factor is the description of purchasing behavior evaluation. Ajzen and Fishbein (2011) claimed that five research studies are confirming the positive influence of the affect factor in purchasing behaviors through reviewing the past literature.

The Perceived Risk Factor can negatively influence purchasing intention. Ajzen and Fishbein (2011) suggest that the meaning of the perceived risk factor is the expectation of future loss because of uncertainty. This loss may be economic loss, mental loss, or the loss of products. When the perceived risk is higher, the possibility of purchasing behaviors happening becomes lower. Jacoby and Kaplan (1972) suggested that there are five types of perceived risk: physiology, mental, society, finance, and process. Since online purchasing behaviors include some exchange of personal information, some customers may perceive some risk in the process of online purchasing behaviors. These risks include the ones from the providers of online goods and online services. For example, the providers of online goods and online services may expose or sell the personal information of customers when there is a lack of effective government regulation. Another risk is from the purchasing environment, including technological facilities. For example, the technology may be out of the control of the providers of online goods and online services. However, once the perceived risk factor decreases, customers prefer to make online purchasing behaviors with a positive attitude and more purchasing intention.

Social factors positively influence purchasing intention. Social factors are shown based on whether or not the purchasing intentions of customers are influenced by society or the other individuals in society. These social factors include some environmental factors like experience, attitude, and value conception system (Triandis, 1980). The influence of social factors is measured by the following indexes: whether the customers are influenced by the tendency of the society, whether the customers are influenced by the individuals of the organizations, and whether the customers are influenced by their family. Triandis (1980) also suggested that there is a significant influence of social factors in purchasing intention because social factors have the function of education. In the website 
environment, the social factors include business advertisement, online information, and third-party guarantees.

Based on the above theories, hypothesis 1 is claimed.

Hypothesis 1: There is a significant influence of some factors, such as affect factors, social factors, and perceived risk factors, in online purchasing intention.

\subsubsection{Identify the Factors of Purchasing Behaviors}

The factor of habit positively influences purchasing behaviors. Triandis (1980) suggested that the meaning of habit is the repeated behaviors owing to the purpose of interests and relaxation. Gefen (2003) claimed that the habit towards technology can influence the attitude towards technology.

The facilitating condition positively influences online purchasing behaviors. It means that the customers consider online purchasing to be conditional. According to the Model of Triandis (1980), facilitating conditions are one of the determining factors of online purchasing behaviors. Triandis (1980) suggested that the effectiveness of resources and the facilitating condition of websites can positively influence online purchasing behaviors. According to the theory of Ajzen and Fishbein (2011), facilitating conditions can influence five emotions of the whole six emotions: like, interest, pride, hate, and failure. He also suggested that the interests of online purchasing behaviors focus on the emotions of like and interest towards the website, which is influenced by its facilitating condition. Some internal environmental factors are also included by the facilitating condition such as the confidence of the customers towards online purchasing behaviors (Ajzen and Fishbein, 2011).

Purchasing intention positively influences purchasing behaviors. Purchasing intention means guiding the customers to use online purchasing behaviors. According to the theory of Ajzen and Fishbein (1970), purchasing intention can directly influence purchasing behaviors because the individual turns to make the behaviors towards which they have a positive attitude. Three indexes can be used to measure the purchasing intention, including whether the customers prefer to choose online purchasing behaviors, whether the customers have online purchasing intention in a short time, and whether the customers have online purchasing intention in a long time. The purchasing intention shows the accepting extent of customers towards purchasing behaviors. Ajzen and Fishbein (1970) also suggested that purchasing intention is a necessary process of making purchasing behaviors so online purchasing intention can be used to predict online purchasing behaviors.

Based on the above theories, hypothesis 2 is claimed.

Hypothesis 2: There is a significant influence of habit, facilitating condition, and purchasing intention in online purchasing behaviors.

\subsubsection{The Summary of the Hypotheses}

From the above discussion, the two hypotheses are presented in the next models.

Hypothesis 1: There is a significant influence of some factors, such as affect 
factors, social factors, and perceived risk factors, in online purchasing intention.

Hypothesis 2: There is a significant influence of habit, facilitating condition, and purchasing intention in online purchasing behaviors.

The summary of these two hypotheses is shown in Figure 6.

\subsection{Whether the Factors Influences Online Purchasing Behavior}

In this part, it explored whether the factors can significantly influence online purchasing behaviors. First, it described the data of the questionnaire. Second, it used principal component analysis to find out the principal components of purchasing intention, considering a large number of factors. Third, it used a multiple linear regression model to test hypothesis 1 . In this part, the principal components are the independent variables. The data of purchasing intention from the questionnaire is the dependent variable. Last, it used the multiple linear regression model to test hypothesis 2 . In this step, the results of purchasing intention, habit, and facilitating conditions from questionnaires are the independent variables, and the data of purchasing are the dependent variables (Table 4).

\subsubsection{The Description of Data}

As is shown in Table 5, eight independent variables influence purchasing intention and their descriptions. There are three affect factors, two social factors, and three perceived risk factors. Each variable is measured through one question in the questionnaire, and the number of samples is 42 for each variable. The minimum is 1 , and the maximum is 5 for all of the eight factors. This shows that some individuals find the factors very satisfactory and also some individuals who find the factors very not satisfactory. Through the comparison of the mean of variables, the largest mean of these eight independent variables is the mean of perceived risk factor 2. This means that the average attitude of perceived risk factor 2 is the most satisfactory among all of the variables. The mean of affect factor 3 is the smallest, which shows that the average attitude towards affect factor 3 is the least satisfactory. Through the comparison of the standard deviation of these eight factors, the standard deviation of affect factor 2 is the largest, which shows that the difference of attitude of the interviewees towards affect

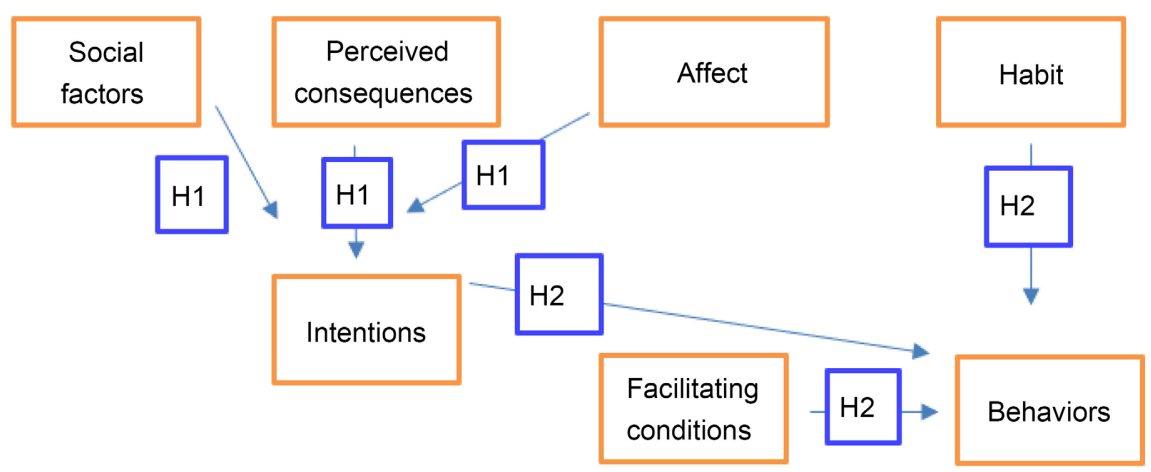

Figure 6. The summary of the hypotheses of the model. 
Table 4. The analysis plan of this part.

\begin{tabular}{|c|c|c|}
\hline The Purpose of this Step & Data & Method \\
\hline Describe The Data & The data of questionnaire & $\begin{array}{l}\text { Using min, max, mean } \\
\text { and average }\end{array}$ \\
\hline $\begin{array}{l}\text { Find Out the Principal } \\
\text { Components }\end{array}$ & $\begin{array}{l}\text { Data of factors from } \\
\text { questionnaire }\end{array}$ & $\begin{array}{l}\text { Using the principal } \\
\text { component analysis }\end{array}$ \\
\hline $\begin{array}{l}\text { The Influence of Components } \\
\text { in Purchasing Intention }\end{array}$ & $\begin{array}{l}\text { Data of components and } \\
\text { purchasing intention from } \\
\text { questionnaire }\end{array}$ & $\begin{array}{l}\text { Using multiple linear } \\
\text { regression model }\end{array}$ \\
\hline $\begin{array}{l}\text { The Influence of Factors in } \\
\text { Purchasing Behavior }\end{array}$ & $\begin{array}{l}\text { Data of purchasing intention, } \\
\text { habit, purchasing behavior and } \\
\text { Facilitating conditions from } \\
\text { questionnaire. }\end{array}$ & $\begin{array}{l}\text { Using multiple linear } \\
\text { regression model }\end{array}$ \\
\hline
\end{tabular}

Table 5. The description of purchasing intention factors.

\begin{tabular}{cccccccc}
\hline \multicolumn{7}{c}{ Description of purchasing intention factors } \\
\hline Variables & $\begin{array}{c}\text { The meaning } \\
\text { of variables }\end{array}$ & Question & $\mathrm{N}$ & Min & Max & Mean & $\begin{array}{c}\text { Standard } \\
\text { deviation }\end{array}$ \\
\hline$F_{1}$ & Affect factor 1 & 1 & 42 & 1 & 5 & 2.76 & 1.358 \\
$F_{2}$ & Affect factor 2 & 2 & 42 & 1 & 5 & 2.60 & 1.563 \\
$F_{3}$ & Affect factor 3 & 3 & 42 & 1 & 5 & 2.21 & 1.335 \\
$F_{4}$ & Social factor 1 & 4 & 42 & 1 & 5 & 2.86 & 1.475 \\
$F_{5}$ & Social factor 2 & 5 & 42 & 1 & 5 & 2.24 & 1.411 \\
$F_{6}$ & Perceived risk factor 1 & 6 & 42 & 1 & 5 & 2.33 & 1.337 \\
$F_{7}$ & Perceived risk factor 2 & 7 & 42 & 1 & 5 & 3.12 & 1.435 \\
$F_{8}$ & Perceived risk factor 3 & 8 & 42 & 1 & 5 & 2.71 & 1.535 \\
\hline
\end{tabular}

factor 2 is larger than the difference of attitude towards other factors. By contrast, the standard deviation of affect factor 3 is the smallest among the eight factors, which shows the difference of attitude towards affect factor 3 is the smallest.

As is discussed in the part of the questionnaire design, there are three questions about the habit and three questions about facilitating conditions. The data of these two variables is calculated by the average of these three related questions. Through the description of variables, the minimum of these four variables is all 1. Only the maximum of purchasing intention and facilitating conditions is 5. The maximum number of habit is 4 , and the max number of purchasing behavior is 3 . Through the comparison of the mean of these four variables, the largest mean is the mean of purchasing intention. The mean of purchasing behaviors is much smaller than the mean of purchasing intention, which shows that the purchasing intention of interviewees is more than the purchasing behaviors of interviewees. This may be because most purchasing behaviors are the 
result of purchasing intention. However, many purchasing intentions cannot result in purchasing behaviors. Through the comparison of the standard deviations of these four variables, the standard deviation of purchasing intention is the largest. By contrast, the standard deviation of purchasing behaviors is the smallest. This means that the difference among the attitude towards purchasing intention is the largest, and the difference among the attitude towards purchasing behaviors is the smallest (Table 6).

\subsubsection{Principal Component Analysis}

In this part, considering there are too many factors of purchasing intention, it used the method of principal component analysis to reduce dimensionality. There are three steps in the method of principal component analysis. Variables were chosen through load capacity, determining the number of principal components, and finding out the data of each component.

\section{1) Choose Variables through Load Capacity}

According to the suggestion of Harris (1968), only the variables with a load capacity of more than 0.5 have statistical significance. This means that this principal component analysis would only use the variables with a load capacity of more than 0.5 to find out the principal components. As is shown in Table 7,

Table 6. The description of purchasing intention factors

\begin{tabular}{cccccccc}
\hline \multicolumn{7}{c}{ Description of purchasing behavior variables } \\
\hline Variables & $\begin{array}{c}\text { The meaning } \\
\text { of variables }\end{array}$ & Question & N & Min & Max & mean & $\begin{array}{c}\text { Standard } \\
\text { deviation }\end{array}$ \\
\hline$x_{1}$ & Purchasing intention & 15 & 42 & 1 & 5 & 2.67 & 1.408 \\
$x_{2}$ & Habit & $9,10,11$ & 42 & 1 & 4 & 2.57 & 0.801 \\
$x_{3}$ & Facilitating conditions & $12,13,14$ & 42 & 1 & 5 & 2.57 & 1.016 \\
$y$ & Purchasing behaviors & 16 & 42 & 1 & 3 & 2.12 & 0.593 \\
\hline
\end{tabular}

The data of $x_{2}$ and $x_{3}$ is calculated by the average of related questions.

Table 7. The load capacity of the factor.

\begin{tabular}{cccc}
\hline Factors & Variables & Initial & Load Capacity of the Factor \\
\hline Affect factor 1 & $F_{1}$ & 1.000 & 0.581 \\
Affect factor 2 & $F_{2}$ & 1.000 & 0.691 \\
Affect factor 3 & $F_{3}$ & 1.000 & 0.366 \\
Social factor 1 & $F_{4}$ & 1.000 & 0.668 \\
Social factor 2 & $F_{5}$ & 1.000 & 0.724 \\
Perceived risk factor 1 & $F_{6}$ & 1.000 & 0.663 \\
Perceived risk factor 2 & $F_{7}$ & 1.000 & 0.681 \\
Perceived risk factor 3 & $F_{8}$ & 1.000 & 0.424 \\
\hline
\end{tabular}

The method of extracting: principal component analysis. 
there are three factors on the affect factor of JD.com. The load capacity of affect factor 1 and affect factor 2 is more than 0.5. This means that these two variables are chosen. However, the load capacity of affect factor 3 is 0.366 , which is less than 0.5. This means that the affect factor 3 is excluded in conducting principal component analysis. Using the same method, there are two social factors with a load capacity greater than 0.5 . This means that both these two factors are chosen in conducting the principal component analysis. The same was also applied to the perceived risk factor. The load capacity of perceived risk factor 1 and perceived risk factor 2 is more than 0.5 . This means that these two factors are included in conducting principal component analysis. By contrast, the load capacity of perceived risk factor 3 is 0.424 , which is less than 0.5 . This means that this factor is excluded from conducting principal component analysis.

\section{2) Determine the Number of Principal Components}

Using SPSS, the result of the explained extent of components is shown in Table 8 . The first component can explain $25.36 \%$ of the purchasing intention. The second component can explain $19.092 \%$ of the purchasing intention. The third component can explain $15.524 \%$ of the purchasing intention. The top three components can explain $59.976 \%$ of the purchasing intention, which is more than $50 \%$. The explained extent of the other components is less than $15 \%$. Therefore, the number of principal components is three.

Figure 7 shows the broken stone of each component. In the figure of the broken stone, the vertical axis is the characteristic value, which shows the explained extent of the components. The horizontal axis is the number of components, which shows how many components are used to explain the variables. In this figure, the line of the explained extent of the first three points decreases sharper than the line of the other points.

\section{3) Find Out the Data of Each Component}

Through the rotated component matrix, the most important influences of the

Table 8. The explained extent of components.

\begin{tabular}{|c|c|c|c|c|c|c|}
\hline \multicolumn{7}{|c|}{ The Explained Extent of Components } \\
\hline \multirow{2}{*}{ Component- } & \multicolumn{3}{|c|}{ Initial Eigenvalues } & \multicolumn{3}{|c|}{ Rotated Sums of Squared Loadings } \\
\hline & Total & $\%$ of variance & Cumulative $\%$ & Total & $\%$ of variance & Cumulative \% \\
\hline 1 & 2.029 & 25.360 & 25.360 & 1.604 & 20.047 & 20.047 \\
\hline 2 & 1.527 & 19.092 & 44.452 & 1.603 & 20.044 & 40.091 \\
\hline 3 & 1.242 & 15.524 & 59.976 & 1.591 & 19.885 & 59.976 \\
\hline 4 & 0.982 & 12.270 & 72.247 & & & \\
\hline 5 & 0.842 & 10.523 & 82.769 & & & \\
\hline 6 & 0.652 & 8.151 & 90.920 & & & \\
\hline 7 & 0.490 & 6.128 & 97.048 & & & \\
\hline 8 & 0.236 & 2.952 & & & & \\
\hline
\end{tabular}




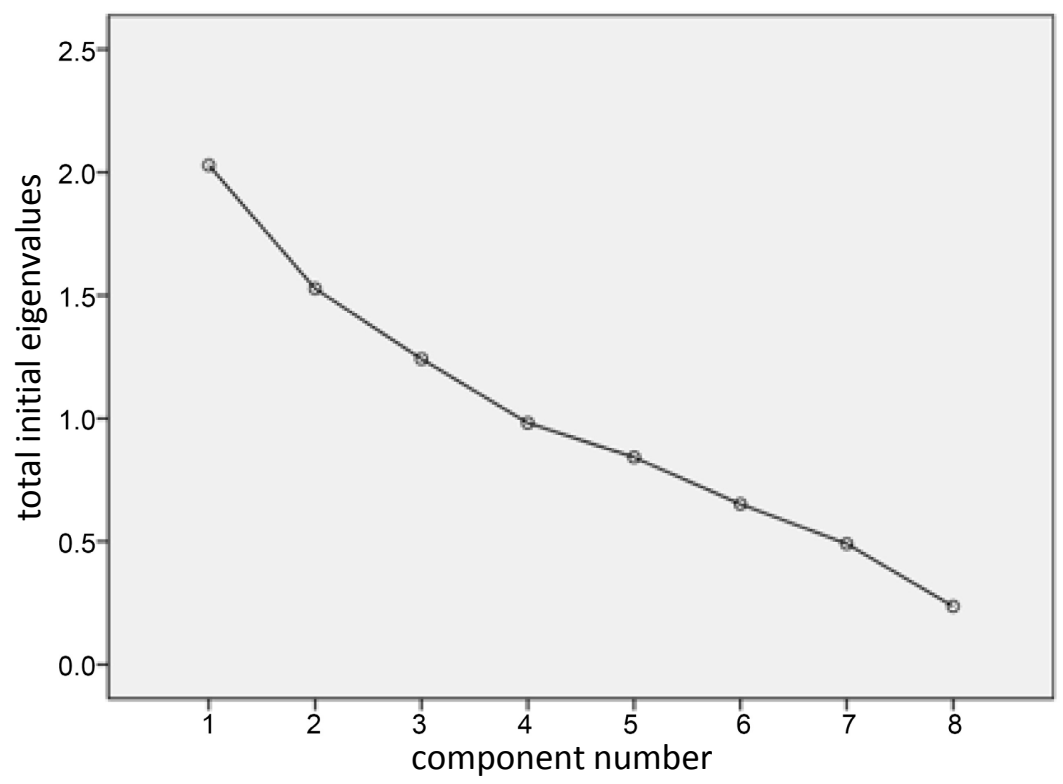

Figure 7. The figure of broken stone.

first component are from affect factor 2 with the score of 0.779 , perceived risk factor 2 with the score of 0.739 , and perceived risk factor 1 with the score of 0.248. This means that component 1 is the affect and risk factor. The most important influence of the second component is from social factor 2, with a score of 0.807. Thus, component 2 is the risk factor. The most important influences of the third component are from affect factor 1 with a score of 0.717 and social factor 1 with a score of 0.210 . Therefore, component 3 is the affect and social factor. In conclusion, there are three principal components in the model: affect and risk factor, risk factor, and affect and social factor (Table 9).

Using SPSS and making each component into a new variable, the component data of the purchasing intention can be obtained, as shown in Table 10. There are 42 data in each component, and each component can be calculated by the following function. In this function, $\mathrm{n}$ is the content that is calculated by the rotated component matrix.

$$
\begin{gathered}
\text { Component } 1=\operatorname{Zscore}\left(F_{2}\right) * 0.779+\operatorname{Zscore}\left(F_{7}\right) * 0.739 \\
+\operatorname{Zscore}\left(F_{6}\right) * 0.248+\cdots+n * \operatorname{Zscore}\left(F_{4}\right) \\
\text { Component } 2=\operatorname{Zscore}\left(F_{5}\right) * 0.807+\cdots+n * \operatorname{Zscore}\left(F_{4}\right) \\
\text { Component } 3=\operatorname{Zscore}\left(F_{1}\right) * 0.717+\operatorname{Zscore}\left(F_{4}\right) * 0.210+\cdots+n * \operatorname{Zscore}\left(F_{4}\right)
\end{gathered}
$$

In this function, component 1 is the affect and risk factor, component 2 is the risk factor, and component 3 is the affect and social factor.

Using the above function, the data of the component is shown in the next tables. In the next step, the multiple linear regression model will use these three components as independent variables. Through this, the purpose of reducing dimensionality is achieved. Eight variables are decreased to three principal components. The data of these three components are shown in Table 11. 
Table 9. Rotated component matrix.

\begin{tabular}{|c|c|c|c|c|c|c|c|c|}
\hline & & & & Component & & & & \\
\hline Factors & Variables & 1 & 2 & 3 & 4 & 5 & 6 & 7 \\
\hline Affect factor 2 & $F_{2}$ & 0.779 & & & & & & \\
\hline Perceived risk factor 2 & $F_{7}$ & 0.739 & & & & & & \\
\hline Perceived risk factor 1 & $F_{6}$ & 0.248 & & & & & & \\
\hline Social factor 2 & $F_{5}$ & & 0.807 & & & & & \\
\hline Affect factor 1 & $F_{1}$ & & & 0.717 & & & & \\
\hline Social factor 1 & $F_{4}$ & & & 0.210 & & & & \\
\hline Result & & $\begin{array}{l}\text { Affect and } \\
\text { risk factor }\end{array}$ & $\begin{array}{l}\text { Risk } \\
\text { factor }\end{array}$ & $\begin{array}{l}\text { Affect and } \\
\text { social factor }\end{array}$ & & & & \\
\hline
\end{tabular}

Table 10. The component data of the purchasing intention.

\begin{tabular}{cccc}
\hline & Component 1 & Component 2 & Component 3 \\
\hline 1 & -1.51 & 0.73 & 0.57 \\
2 & 0.18 & 0.61 & -1.37 \\
3 & 1.60 & 1.33 & -1.03 \\
$\ldots$ & $\ldots$ & $\ldots$ & $\ldots$ \\
42 & -0.80 & 1.51 & -0.81 \\
\hline
\end{tabular}

Table 11. The coefficient of the model.

\begin{tabular}{cccccc}
\hline \multicolumn{7}{c}{ coefficient } \\
\hline Variables & B & $\begin{array}{c}\text { Standard } \\
\text { error }\end{array}$ & $\begin{array}{c}\text { Standard } \\
\text { coefficient }\end{array}$ & $\mathrm{t}$ & Sig. \\
\hline Constant & 2.665 & 0.092 & Beta & 28.817 & ${ }^{* * *} 0.000$ \\
component 1 & 0.715 & 0.087 & 0.549 & 8.221 & ${ }^{* * *} 0.000$ \\
component 2 & 0.640 & 0.089 & 0.476 & 7.161 & ${ }^{* * *} 0.000$ \\
component 3 & 0.817 & 0.090 & 0.648 & 9.693 & ${ }^{* *} 0.000$ \\
\hline
\end{tabular}

${ }^{\star} p<0.05 ;{ }^{* *} p<0.01 ;{ }^{* *} p<0.001$; Significance Level $=0.05$. Dependent variable: purchasing intention.

\subsubsection{Multiple Linear Regression Model of Purchasing Intention}

In this part, the multiple linear regression model is used to test hypothesis 1.

Hypothesis 0: There is no significant influence of components in purchasing intention.

Hypothesis 1: There is a significant influence of components in purchasing intention.

The dependent variable is the data of purchasing intention from the questionnaire. The independent variables are component 1 , component 2 , and component 3 which are obtained from the method of principal component analysis. 
Using the dependent variable and independent variables to make a multiple linear regression model, the result is shown in the following table.

The standard error is used to measure the stability and effectiveness of the coefficient. When the standard error is lesser, the coefficient is more stable and effective. In this model, all of the standard errors are less than 0.1. This means that the coefficients of this model are stable and effective.

The standard coefficient in beta is used to measure the extent of influence of these independent variables in dependent variables. Among the beta of these three components, the beta of component 3, which is affect and social factor, is the largest. This means that the influence of affect and social factors is larger than the influence of the other two factors. By contrast, the beta of component 2, which is the risk factor, is smaller than the other two components. This means that the influence of component 2 is the smallest.

The $p$-value, which is shown in the last line, is used to measure whether the influence is significant. If the $p$-value is less than 0.05 , the influence of these independent variables in dependent variables is significant with the $95 \%$ confidence interval. In this model, because the $p$ values of these three components are all less than 0.05 , Hypothesis 0 is rejected with the $95 \%$ confidence interval. This means that there is a significant influence of these three components in purchasing intention with the $95 \%$ confidence interval.

The coefficients of these three variables are all positive, which means that the influences of these three components in purchasing intention are all positive with the $95 \%$ confidence interval. Using the line of coefficients, this model can be written as this function:

$$
\begin{aligned}
\text { Purchasing intention }= & \text { component } 1 * 0.715+0.640 * \text { component } 2 \\
& +0.817 * \text { component } 3+2.665
\end{aligned}
$$

In this function, component 1 is the affect and risk factor, component 2 is the risk factor, and component 3 is the affect and social factor.

According to the theory of Field (2013), R square is used to measure the extent of independent variables for explaining the change of dependent variable. This means that $\mathrm{R}$ square explains how much the independent variables explain the dependent variable. In the table of the summary of the model (Table 12), the $\mathrm{R}$ square is 0.833 , which is more than 0.8 . This means that the independent variables, which are the three components, can explain $83.3 \%$ of the change of the purchasing intention. The $\mathrm{R}$ square shows that the multiple linear regression model can explain purchasing intention well (Field, 2013).

Table 12. The summary of the model.

\begin{tabular}{ccccc}
\hline $\mathrm{R}$ & R square & Adjusted R square & Standard error & Durbin-Waston \\
\hline 0.913 & 0.833 & 0.819 & 0.598 & 2.190 \\
\hline
\end{tabular}

Significance Level $=0.05$. Dependent variable: purchasing intention. Independent variable: Component 1, 2 and 3. 
Moreover, according to the theory of Field (2013), Durbin-Waston is used to measure the sequence correlation of error. If the Durbin-Waston is near to 2, there is no sequence correlation of error. By contrast, if the Durbin-Waston is near 0 , there is a positive sequence correlation of error. If the Durbin-Waston is near to 4 , there is a negative sequence correlation of error. In this model, the Durbin-Waston is near to 2 , which means that there is no sequence correlation of error in this model.

Moreover, the summary standard error of this model is small, which means that the coefficients of this model are stable and effective.

In summary, there are significant positive influences of affect and risk factor, risk factor and affect, and social factor in purchasing intention. Hypothesis 1 is accepted with the $95 \%$ confidence interval. The influence of affect and social factors is larger than the influence of the other two factors. This model can explain the purchasing intention well, and the coefficients of this model are stable and effective. Further, it shows that there is no sequence correlation of error in this model.

\subsubsection{Multiple Linear Regression Model of Purchasing Behaviors}

In this part, multiple linear regression models were used to test Hypothesis 2.

Hypothesis 0: There is no significant influence of habit, facilitating condition, and purchasing intention in online purchasing behaviors.

Hypothesis 2: There is a significant influence of habit, facilitating condition, and purchasing intention in online purchasing behaviors.

The dependent variable is the data of purchasing behavior from the questionnaire. The independent variables are the data of habit, facilitating condition, and purchasing intention from the questionnaire. Using the dependent variable and independent variables to make a multiple linear regression model, the result is shown in the following Table 13.

In this model, all of the standard errors are less than 0.3 . Therefore, the coefficients of this model are stable and effective, and the results of the model are meaningful.

Table 13. The coefficient of the model.

\begin{tabular}{cccccc}
\hline \multicolumn{5}{c}{ Coefficient } \\
\hline Variables & B & Standard error & $\begin{array}{c}\text { Standard } \\
\text { coefficient }\end{array}$ & $t$ & Sig. \\
\hline Constant & -0.261 & 0.215 & Beta & -1.216 & 0.232 \\
$x_{1}$ & 0.368 & 0.032 & 0.868 & 11.404 & ${ }^{* *} 0.000$ \\
$x_{2}$ & 0.413 & 0.055 & 0.570 & 7.474 & ${ }^{* *} 0.000$ \\
$x_{3}$ & 0.130 & 0.041 & 0.228 & 3.163 & ${ }^{*} 0.003$ \\
\hline
\end{tabular}

${ }^{\star} p<0.05 ;{ }^{* *} p<0.01 ;{ }^{* *} p<0.001$; Significance Level $=0.05$. Dependent variable: purchasing behaviors. 
In terms of standard coefficient, among the beta of these three factors, the beta of variable $x_{1}$, which is purchasing intention, is the largest. This means that the influence of purchasing intention is larger than the influence of habit and facilitating conditions. By contrast, the beta of $x_{3}$, which is the facilitating condition, is smaller than the other two variables. This means that the influence of facilitating conditions is the smallest. In this model, because the $p$ values of these three independent variables are all less than 0.05, Hypothesis 0 is rejected with the $95 \%$ confidence interval. This means that there is a significant influence of habit, facilitating condition, and purchasing intention in online purchasing behaviors with the $95 \%$ confidence interval.

The coefficients of these three independent variables are all positive, which means that the influences of habit, facilitating condition, and purchasing intention in online purchasing behaviors are all positive with the $95 \%$ confidence interval. Using the coefficients that are shown in the first line, this model can be written with this function:

$$
\text { Purchasing behavior }(y)=x_{1} * 0.368+0.413 * x_{2}+0.130 * x_{3}-0.261
$$

In this function, $x_{1}$ means the purchasing intention, $x_{2}$ means habit, and $x_{3}$ means the facilitating condition.

In the table of the summary of the model (Table 14), the R square is 0.809 , which is more than 0.8 . This means that the habit, facilitating condition, and purchasing intention can explain $80.9 \%$ of the change in the purchasing behaviors. Further, the $\mathrm{R}$ square shows that the multiple linear regression model can explain purchasing intention well. Moreover, the summary standard error of this model is small, which is 0.265 . This means that the coefficients of this model are stable and effective.

In summary, there are significant positive influences of habit, facilitating condition, and purchasing intention in online purchasing behaviors. Hypothesis 2 is accepted with the $95 \%$ confidence interval. This means that the influence of purchasing intention is larger than the influence of the other two factors. The model can also explain the purchasing behavior well and the coefficients of this model are stable and effective.

\subsubsection{The Result of the Models}

The results show that there are four steps in the mathematical model. In the first step, it described the data from the questionnaire using min, max, mean and average. It shows that the purchasing behavior is less than the purchasing intention. The affect factor 3 of JD.com is the least satisfactory, and the perceived risk

Table 14. The summary of the model.

\begin{tabular}{cccc}
\hline $\mathrm{R}$ & R square & Adjusted R square & Standard error \\
\hline 0.900 & 0.809 & 0.794 & 0.265 \\
\hline
\end{tabular}

Significance Level $=0.05$. Dependent variable: purchasing behaviors. Independent variable: purchasing intention, habit and Facilitating conditions. 
Table 15. The result of models.

\begin{tabular}{lll}
\hline \multicolumn{1}{c}{ The Step } & \multicolumn{1}{c}{ Method } & \multicolumn{1}{c}{ Results } \\
\hline Describe the Data & $\begin{array}{l}\text { Using min, max, } \\
\text { mean and average }\end{array}$ & $\begin{array}{l}\text { The description of the data from the } \\
\text { questionnaire. }\end{array}$ \\
\hline $\begin{array}{l}\text { Find out the Principal } \\
\text { Components }\end{array}$ & $\begin{array}{l}\text { Using the principal } \\
\text { component analysis }\end{array}$ & $\begin{array}{l}\text { Three components: affect and risk } \\
\text { factor, risk factor and affect, and } \\
\text { social factor. }\end{array}$ \\
$\begin{array}{l}\text { The Influence of } \\
\text { Components in } \\
\begin{array}{l}\text { Purchasing Intention } \\
\text { regression model }\end{array}\end{array}$ & $\begin{array}{l}\text { Significant positive influence of } \\
\text { components in purchasing } \\
\text { intention }\end{array}$ \\
$\begin{array}{l}\text { The Influence of Factors } \\
\text { in Purchasing Behavior }\end{array}$ & $\begin{array}{l}\text { Using multiple linear } \\
\text { regression model }\end{array}$ & $\begin{array}{l}\text { Significant positive influence of } \\
\text { habit, facilitating condition and } \\
\text { purchasing intention in online } \\
\text { purchasing behaviors }\end{array}$ \\
\hline
\end{tabular}

factor 2 is the most satisfactory. In the second step, through the principal component analysis, 8 factors can be reduced into three principal components: affect and risk factor, risk factor, and affect and social factor. In the third step, there is a significant positive influence of components in purchasing intention with the $95 \%$ confidence interval. It shows that the influence of affect and social factors is larger than the influence of the other two factors. In the last step, there is a significant positive influence of habit, facilitating condition, and purchasing intention in online purchasing behaviors with the $95 \%$ confidence interval. It shows that the influence of purchasing intention is larger than the influence of the other two factors (Table 15).

In summary, through the case of JD.com, habit, facilitating condition, and purchasing intention can positively influence purchasing behaviors directly. Affect factors, social factors, and risk factors can positively influence purchasing behaviors indirectly through influencing purchasing intention. The largest influence of purchasing behaviors is from purchasing intention. The largest influence of purchasing intention is from affect and social factors.

\section{Findings and Recommendations}

\subsection{Discussion of Findings}

This research reveals four characteristics of online purchasing behavior in the case of JD.com. The first characteristic is that the customers of online purchasing in JD.com pay more attention to the quality of the goods. Another characteristic is that the price is still the most important factor that the customers consider.

The third characteristic is that there are different characteristics of the online purchasing behavior of JD.com in different cities. The last characteristic is that the website has a quick speed of development. 
In terms of the factors of the online purchasing behaviors, there are six factors, namely the affect factors, social factors, perceived risk factors, habit, facilitating condition, and purchasing intention.

1) Affect Factors

Through the model of this research, there is a positive influence of affect factors in online purchasing intention. Due to the positive influence of online purchasing intention in online purchasing behaviors, affect factors can positively influence online purchasing behaviors indirectly. Further, the results show that there is a relationship between emotion and online purchasing behaviors in the case of JD.com. This relationship can be used to increase online purchasing behaviors and positive attitudes towards online purchasing by making customers experience the satisfactory and smooth process of online purchasing on the website of JD.com.

2) Social Factors

Through the result of the multiple linear regression model, social factors can positively influence online purchasing intention, which can also positively influence online purchasing behaviors. Thus, there is a positive influence of social factors in online purchasing behaviors.

Further, the results show that there are two types of social factors. One is the individual factor, including the suggestions and views from the family and friends of the customers. The other is the un-individual factor, including the advertisement on the website and the suggestions from specialists. In the case of JD.com, the social factors also include the information on the website and the information from product tests. Through these, JD.com and other online shopping malls can improve the online purchasing behaviors of the customers by building a good social environment that can guide customers to shop online.

3) Perceived Risk Factors

Through the multiple linear regression model of this research, the online purchasing intention will increase if the perceived risk decreases. This means that there is an inverse or negative relationship between perceived risk factors and online purchasing intention. Similarly, perceived risk factors negatively influence online purchasing behaviors in the case of JD.com.

In this research, there are many parts of online risk like the loss of money, the possibility of buying fake goods, and unexpected loss. Through these, the website of JD.com can improve online purchasing behaviors by decreasing the expected and unexpected loss of customers.

4) Habit

According to the results of the multiple linear regression model, the habit has a significant influence on online purchasing behaviors. Habit can positively influence online purchasing behaviors directly. However, the influence of habit is smaller than the influence of online purchasing intention. This may be because online shopping is a new thing in some cities. This means that the habit has not been formed. Some individuals choose to use online shopping because of the 
cost of purchasing and the types of online goods. Also, some customers may choose to purchase online because of curiosity. However, with the development of online purchasing and websites, individuals will form the habit of online purchasing in the future. As time goes, the positive influence of habit in online purchasing behaviors will be increasingly large.

5) Facilitating Condition

Through the result of the multiple linear regression model of this thesis, facilitating conditions can directly influence the online purchasing behaviors in the case of JD.com, which is the same as the views of Triandis (1980). Triandis (1980) suggested that the skills of the users of the website and the effective resource can directly influence online purchasing behaviors. Moreover, in the case of JD.com, the facilitating condition includes some resources of online shopping, such as the equipment of the Internet, time and money of the customers, and the self-evaluation of the customers' purchasing ability. Thus, in the process of improving the number of customers, guiding the customers with enough ability of online purchasing is necessary. However, according to the beta of the multiple linear regression model, the influence of facilitating conditions is smaller than the influence of the other factors.

6) Purchasing Intention

The influence of online purchasing intention in online purchasing behaviors is larger than the other two factors. Through the multiple linear regression model and principal component analysis using the case of JD.com, online purchasing intention is influenced by affect factors, social factors, and perceived risk factors. With these, the online shopping malls should pay attention to increasing the purchasing intention of customers.

\subsection{Recommendations}

As discussed in the above chapters, there are three indirect factors of online purchasing behaviors. These three factors influence online purchasing behaviors through influencing online purchasing intention.

Moreover, there are three direct factors of online purchasing behaviors. The influences of all six factors are significant.

As the researcher's recommendations:

To improve the affect factors, JD.com and other online shopping malls can make customers experience a satisfactory and smooth process of online purchasing through improving the website and increasing the quality of the service. To improve the social factors, JD.com and other online shopping malls can build a good social environment that can guide customers to shop online through improving the advertisement and addressing the suggestions from the family and friends of the customers. To improve the perceived risk factors, JD.com and other online shopping malls can increase the quality of the goods and supervise the merchants of the website to decrease the expected loss and unexpected loss of customers. To improve the habit factors, JD.com and other online shopping 
malls can guide the customers to purchase online more frequently to develop the online purchasing habits of the customers. To improve the facilitating condition factors, JD.com and other online shopping malls can guide the customers with good ability of online purchasing and enough economic ability.

\subsection{Conclusion and Summary}

This research explores the factors of online purchasing behaviors and the extent of the impact of these factors using the case of JD.com. Through various analyses, this research found out three indirect factors of online purchasing behaviors and three direct factors of online purchasing behaviors. However, there are still limitations in this research. Hence, future researchers still need to explore some specific methods and activities to improve the online purchasing behaviors of JD.com and other online shopping malls. Moreover, future research studies with different approaches to data can be conducted to fill in the other research gaps that are not included in this study.

\section{Conflicts of Interest}

The authors declare no conflicts of interest regarding the publication of this paper.

\section{References}

Ajzen, I. (1985). From Intentions to Actions: A Theory of Planned Behavior. In J. Kuhl, \& J. Beckmann (Eds.), Action Control (pp. 11-39). Springer. https://doi.org/10.1007/978-3-642-69746-3 2

Ajzen, I., \& Fishbein, M. (1970). The Prediction of Behavior from Attitudinal and Normative Variables. Journal of Experimental Social Psychology, 6, 466-487. https://doi.org/10.1016/0022-1031(70)90057-0

Ajzen, I., \& Fishbein, M. (2005). The Influence of Attitudes on Behavior. In D. Albarracín, B. T. Johnson, \& M. P. Zanna (Eds.), The Handbook of Attitudes (pp. 173-221). Lawrence Erlbaum Associates.

Ajzen, I., \& Fishbein, M. (2008). Scaling and Testing Multiplicative Combinations in the Expectancy-Value Model of Attitudes. Journal of Applied Social Psychology, 38, 2222-2247. https://doi.org/10.1111/j.1559-1816.2008.00389.x

Ajzen, I., \& Fishbein, M. (2011). Attitudes and the Attitude-Behavior Relation: Reasoned and Automatic Processes. European Review of Social Psychology, 11, 1-33. https://doi.org/10.1080/14792779943000116

Bitner, M. J. (1992). Servicescapes: The Impact of Physical Surroundings on Customers and Employees. Journal of Marketing, 56, 57-71. https://doi.org/10.1177/002224299205600205

Chiu, W., \& Choi, H. (2018). Consumers' Goal-Directed Behavior of Purchasing Sportswear Products Online: A Case Study of Chinese Consumers. Sport, Business and Management, 8, 118-133. https://doi.org/10.1108/SBM-03-2017-0020

Cox, D. F., \& Rich, S. U. (1964). Perceived Risk and Consumer Decision-Making-The Case of Telephone Shopping. Journal of Marketing Research, 1, 32-39.

https://doi.org/10.1177/002224376400100405 
Eroglu, S. A., Machleit, K. A., \& Davis, L. M. (2003). Empirical testing of a model of online store atmospherics and shopper responses. Psychology \& Marketing, 20, 139-150. https://doi.org/10.1002/mar.10064

Field, A. (2013) Discovering Statistics Using SPSS. Sage.

Gefen, D. (2003). TAM or Just Plain Habit. Journal of Organizational and End User Computing, 15, 1-13. https://doi.org/10.4018/joeuc.2003070101

Glandon, T. A., \& Haynes, C. M. (2005). Past Purchasing Behavior in E-Commerce: The Impact on Intentions to Shop Online. In N. Shin (Ed.), Strategies for Generating E-Business Returns on Investment (pp. 209-234). IGI Global. https://doi.org/10.4018/978-1-59140-417-0.ch010

Harris, C. C. (1968). The Application of Size Distribution Equations to Multi-Event Comminution Process. Transactions SME/AIME, 241, 343-358.

Hoffman, D. L., Kalsbeek, W. D., \& Novak, T. P. (1996). Internet and Web Use in the U.S. Communications of the ACM, 39, 36-46. https://doi.org/10.1145/240483.240490

Jacoby, J., \& Kaplan, L. B. (1972). The Components of Perceived Risk. Advances in Consumer Research, 3, 382-383.

Jarvenpaa, S. L., \& Todd, P. A. (1996). Consumer Reactions to Electronic Shopping on The World Wide Web. International Journal of Electronic Commerce, 1, 59-88.

https://doi.org/10.1080/10864415.1996.11518283

JD.com. (n.d.). About Us. JD.Com, Inc. https://corporate.jd.com/aboutUs

Kandampully, J., \& Butler, L. (2001). Service Guarantees: A Strategic Mechanism to Minimise Customers' Perceived Risk in Service Organizations. Journal of Service Theory \& Practice, 11, 112-121. https://doi.org/10.1108/09604520110387248

Krairiksh, M., \& Anthony, M. K. (2001). Benefits and Outcomes of Staff Nurses' Participation in Decision Making. JONA, 31, 16-23. https://doi.org/10.1097/00005110-200101000-00005

Lopez-Nicolas, C., \& Francisco, J. M.-C. (2008). Customer Knowledge Management and E-Commerce: The Role of Customer Perceived Risk. International Journal of Information Management, 28, 102-113. https://doi.org/10.1016/j.ijinfomgt.2007.09.001

Ma, Y. (2021, September 22). Number of Online Shoppers in China 2009-2020. Statista. https://www.statista.com/statistics/277391/number-of-online-buyers-in-china/

Mehrabian, A., \& Russell, J. A. (1974). A Verbal Measure of Information Rate for Studies in Environmental Psychology. Environment \& Behavior, 6, 233-252.

https://doi.org/10.1177/001391657400600205

Ramin, A., Darush, S., \& Mohammad, E. T. (2011). The Role of Security as a Customer Perception on Customers' Online Purchasing Behavior. In International Proceedings of Computer Science and Information Technology, International Conference on Software and Computer Application (Vol. 9, pp. 174-181). IACSIT Press.

Sheppard, B. H., Hartwick, J., \& Warshaw, P. R. (1988). The Theory of Reasoned Action: A Meta-Analysis of Past Research with Recommendations for Modifications and Future Research. Journal of Consumer Research, 15, 325-343. https://doi.org/10.1086/209170

Sun, G., Shen, F., \& Ma, X. (2021). The Influence of Face on Online Purchases: Evidence from China. Frontiers in Psychology, 12, Article ID: 788063. https://doi.org/10.3389/fpsyg.2021.788063

Triandis, H. C. (1980). Values, Attitudes, and Interpersonal Behavior. Nebraska Symposium on Motivation, 27, 195-259. 
Tsai, J. Y., Egelman, S., Cranor, L., \& Acquisti, A. (2001). The Effect of Online Privacy Information on Purchasing Behavior: An Experimental Study. Information Systems Research, 22, 254-268. https://doi.org/10.1287/isre.1090.0260 


\section{Appendix 1: The Questionnaire}

Please score for the next 16 questions. The score of 1 means strongly disagree with the questions. The score of 2 means disagree. The score of 3 means neutral. The score of 4 means agree with the questions. The score of 5 means strongly agree with the questions.

1) I like to make online purchasing in the website of JD.

2) I think that online purchasing in the website of JD is very interesting.

3) I think that online purchasing in the website of JD is a good way to shop.

4) I will consider the suggestions of my friends and family in the process of online purchasing in the website of JD.

5) I will pay attention to the evaluations of other customers in the process of online purchasing in the website of JD.

6) There are some risks in the process of online purchasing in the website of JD, such as disclosuring the personal information, buying fake goods and loss of money.

7) Online purchasing in the website of JD may lead to some unhoped loss.

8) There is no risk in the process of online purchasing in the website of JD.

9) I will firstly choose online purchasing in the website of JD when I want to shop.

10) I will firstly think of online purchasing in the website of JD when I want to shop.

11) I am used to online purchasing in the website of JD.

12) Using computer or mobile phone to online purchase in the website of JD is easy for me.

13) I have many time to online purchase in the website of JD.

14) I have enough money to online purchase in the website of JD.

15) I prefer to online purchase in the website of JD.

16) I have many experiences of online purchasing in the website of JD.

\section{Appendix 2}

\section{The Data of the Questionnaire}

\begin{tabular}{|c|c|c|c|c|c|c|c|c|c|c|c|c|c|c|}
\hline $\begin{array}{c}\text { Affect } \\
1\end{array}$ & $\begin{array}{c}\text { Affect } \\
2\end{array}$ & $\begin{array}{c}\text { Affect } \\
3\end{array}$ & $\begin{array}{c}\text { Social } \\
1\end{array}$ & $\begin{array}{c}\text { Social } \\
2\end{array}$ & Risk 1 & $\begin{array}{c}\text { Risk } \\
2\end{array}$ & $\begin{array}{c}\text { Risk } \\
3\end{array}$ & $\begin{array}{c}\text { Habit } \\
1\end{array}$ & $\begin{array}{c}\text { Habit } \\
2\end{array}$ & Habit 3 & $\begin{array}{c}\text { Condition } \\
1\end{array}$ & $\begin{array}{c}\text { Condition } \\
2\end{array}$ & $\begin{array}{c}\text { Condition } \\
3\end{array}$ & $\begin{array}{c}\text { Purchasing } \\
\text { Intention }\end{array}$ \\
\hline 3 & 1 & 1 & 2 & 3 & 1 & 1 & 3 & 3 & 2 & 5 & 2 & 4 & 3 & 2 \\
\hline 2 & 2 & 2 & 1 & 3 & 5 & 3 & 3 & 3 & 2 & 4 & 3 & 3 & 3 & 2 \\
\hline 2 & 5 & 3 & 1 & 4 & 5 & 4 & 3 & 3 & 1 & 2 & 1 & 2 & 5 & 4 \\
\hline 1 & 2 & 2 & 4 & 4 & 2 & 3 & 5 & 3 & 1 & 2 & 2 & 2 & 1 & 1 \\
\hline 2 & 1 & 2 & 1 & 3 & 1 & 1 & 2 & 1 & 1 & 1 & 1 & 1 & 3 & 3 \\
\hline 3 & 4 & 4 & 1 & 2 & 2 & 2 & 1 & 1 & 2 & 1 & 1 & 1 & 1 & 5 \\
\hline 2 & 1 & 2 & 1 & 2 & 5 & 3 & 1 & 3 & 2 & 1 & 1 & 1 & 5 & 1 \\
\hline
\end{tabular}




\section{Continued}

\begin{tabular}{|c|c|c|c|c|c|c|c|c|c|c|c|c|c|c|}
\hline 3 & 1 & 1 & 4 & 1 & 2 & 2 & 4 & 2 & 4 & 4 & 5 & 4 & 3 & 1 \\
\hline 3 & 2 & 2 & 2 & 2 & 1 & 2 & 1 & 3 & 3 & 4 & 2 & 3 & 5 & 3 \\
\hline 1 & 3 & 5 & 2 & 3 & 4 & 4 & 1 & 3 & 4 & 3 & 1 & 1 & 2 & 3 \\
\hline 1 & 2 & 1 & 2 & 2 & 1 & 2 & 1 & 4 & 4 & 2 & 2 & 2 & 1 & 2 \\
\hline 3 & 1 & 1 & 5 & 1 & 3 & 1 & 3 & 5 & 4 & 2 & 5 & 3 & 1 & 1 \\
\hline 2 & 1 & 1 & 5 & 2 & 2 & 1 & 5 & 5 & 4 & 1 & 2 & 2 & 4 & 1 \\
\hline 3 & 1 & 1 & 5 & 1 & 2 & 1 & 1 & 4 & 2 & 2 & 1 & 2 & 1 & 1 \\
\hline 3 & 1 & 2 & 5 & 2 & 3 & 2 & 2 & 4 & 2 & 3 & 4 & 4 & 1 & 1 \\
\hline 4 & 4 & 5 & 5 & 2 & 1 & 2 & 2 & 1 & 2 & 2 & 1 & 2 & 1 & 4 \\
\hline 5 & 4 & 3 & 3 & 1 & 1 & 5 & 1 & 3 & 5 & 1 & 3 & 1 & 3 & 5 \\
\hline 5 & 4 & 5 & 5 & 1 & 1 & 5 & 2 & 2 & 5 & 2 & 2 & 1 & 5 & 4 \\
\hline 4 & 2 & 1 & 3 & 1 & 1 & 5 & 1 & 2 & 5 & 1 & 2 & 1 & 1 & 2 \\
\hline 4 & 2 & 1 & 2 & 1 & 2 & 5 & 2 & 3 & 5 & 2 & 3 & 2 & 2 & 2 \\
\hline 1 & 2 & 2 & 3 & 1 & 4 & 3 & 2 & 3 & 4 & 4 & 1 & 3 & 4 & 1 \\
\hline 3 & 5 & 1 & 3 & 1 & 3 & 3 & 2 & 2 & 1 & 2 & 1 & 4 & 4 & 3 \\
\hline 2 & 3 & 4 & 4 & 1 & 3 & 4 & 5 & 1 & 3 & 1 & 3 & 5 & 4 & 2 \\
\hline 2 & 2 & 1 & 2 & 1 & 4 & 4 & 5 & 2 & 2 & 1 & 5 & 5 & 4 & 1 \\
\hline 5 & 1 & 3 & 1 & 3 & 5 & 4 & 5 & 1 & 2 & 1 & 1 & 4 & 2 & 3 \\
\hline 3 & 1 & 1 & 5 & 1 & 2 & 5 & 1 & 4 & 4 & 2 & 2 & 2 & 1 & 1 \\
\hline 2 & 1 & 2 & 5 & 2 & 3 & 5 & 3 & 5 & 4 & 2 & 5 & 3 & 1 & 1 \\
\hline 3 & 1 & 4 & 3 & 2 & 3 & 4 & 5 & 5 & 4 & 1 & 2 & 2 & 4 & 2 \\
\hline 3 & 1 & 3 & 3 & 2 & 2 & 1 & 1 & 4 & 2 & 2 & 1 & 2 & 1 & 2 \\
\hline 4 & 1 & 3 & 4 & 5 & 1 & 3 & 2 & 4 & 2 & 3 & 4 & 4 & 1 & 4 \\
\hline 2 & 1 & 4 & 4 & 5 & 2 & 2 & 2 & 1 & 2 & 2 & 1 & 2 & 1 & 3 \\
\hline 5 & 4 & 3 & 3 & 1 & 1 & 5 & 1 & 3 & 5 & 1 & 3 & 1 & 3 & 5 \\
\hline 5 & 4 & 5 & 5 & 1 & 1 & 5 & 2 & 2 & 5 & 2 & 2 & 1 & 5 & 4 \\
\hline 1 & 5 & 1 & 3 & 1 & 3 & 5 & 4 & 2 & 5 & 3 & 2 & 2 & 1 & 2 \\
\hline 1 & 5 & 2 & 2 & 1 & 5 & 5 & 4 & 1 & 2 & 2 & 5 & 1 & 3 & 2 \\
\hline 1 & 5 & 1 & 2 & 1 & 1 & 4 & 2 & 2 & 1 & 2 & 5 & 2 & 2 & 3 \\
\hline 2 & 5 & 2 & 3 & 2 & 2 & 4 & 2 & 3 & 4 & 4 & 5 & 1 & 2 & 4 \\
\hline 5 & 5 & 2 & 1 & 2 & 2 & 1 & 2 & 2 & 1 & 2 & 1 & 4 & 4 & 5 \\
\hline 3 & 3 & 1 & 1 & 5 & 1 & 3 & 5 & 1 & 3 & 1 & 3 & 5 & 4 & 5 \\
\hline 5 & 5 & 1 & 1 & 5 & 2 & 2 & 5 & 2 & 2 & 1 & 5 & 5 & 4 & 5 \\
\hline 1 & 3 & 1 & 1 & 5 & 1 & 2 & 5 & 1 & 2 & 1 & 1 & 4 & 2 & 4 \\
\hline 1 & 2 & 1 & 2 & 5 & 2 & 3 & 5 & 2 & 3 & 2 & 1 & 3 & 5 & 2 \\
\hline
\end{tabular}

